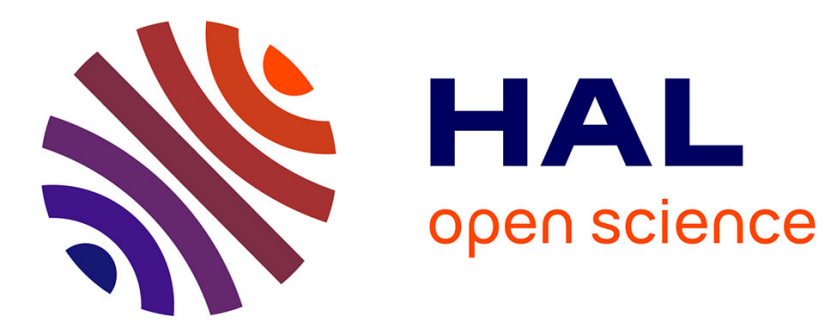

\title{
Image-based mapping of surface fissures for the investigation of landslide dynamics
}

André Stumpf, Jean-Philippe Malet, Norman Kerle, Uwe Niethammer, Sabrina Rothmund

\section{To cite this version:}

André Stumpf, Jean-Philippe Malet, Norman Kerle, Uwe Niethammer, Sabrina Rothmund. Imagebased mapping of surface fissures for the investigation of landslide dynamics. Geomorphology, 2012, 186, pp.12-27. 10.1016/j.geomorph.2012.12.010 . hal-00788159

\section{HAL Id: hal-00788159 \\ https://hal.science/hal-00788159}

Submitted on 2 Mar 2013

HAL is a multi-disciplinary open access archive for the deposit and dissemination of scientific research documents, whether they are published or not. The documents may come from teaching and research institutions in France or abroad, or from public or private research centers.
L'archive ouverte pluridisciplinaire HAL, est destinée au dépôt et à la diffusion de documents scientifiques de niveau recherche, publiés ou non, émanant des établissements d'enseignement et de recherche français ou étrangers, des laboratoires publics ou privés. 


\section{Image-based mapping of surface fissures for the investigation of landslide 2 dynamics}

4 André Stumpf (1,2,3), Jean-Philippe Malet (2), Norman Kerle (3), Uwe Niethammer (4), Sabrina $5 \quad$ Rothmund (4)

(1) Laboratoire Image, Ville, Environnement, CNRS ERL 7230, University of Strasbourg, France

(2) Institut de Physique du Globe de Strasbourg, CNRS UMR 7516, University of Strasbourg, France

(3) Faculty of Geo-Information Science and Earth Observation - ITC, University of Twente, Enschede,

10 The Netherlands

11 (4) Institut für Geophysik, University of Stuttgart, Stuttgart, Germany

Abstract

14 The development of surface fissures is an important indicator for understanding and forecasting slope 15 movements. Landslide investigations therefore frequently include the elaboration and interpretation of 16 maps representing their spatial distribution, typically comprising intensive field work and 17 instrumentation. Only recently aerial photography with sub-decimetre spatial resolution is becoming more 18 commonly available and opens a window to analyse such features from a remote sensing perspective.

19 While these data are in principle helpful to elaborate maps from image interpretation techniques, there is 20 still no image processing technique available to extract efficiently these geomorphological features. This 21 work proposes a largely automated technique for the mapping of landslide surface fissures from very-high

22 resolution aerial images. The processing chain includes the use of filtering algorithms and post-processing 23 of the filtered images using object-oriented analysis. The accuracy of the resulting maps is assessed by 24 comparisons with several expert maps in terms of affected area, fissure density and fissure orientation. 25 Under homogenous illumination conditions, true positive rates up to $65 \%$ and false positive rates 26 generally below $10 \%$ are achieved. The resulting fissure maps provide sufficient detail to infer 
27 mechanical processes at the slope scale and to prioritize areas for more detailed ground investigations or

28 monitoring.

\section{Keywords:}

31 Landslide; Fissure; Geomorphological mapping; Remote sensing; Image filtering; UAV

\section{Introduction}

35 Observations of features and structural patterns of earth surface landforms can reveal information on the 36 origin and mechanisms controlling the geomorphological processes. Structural geology and 37 geomorphology have developed comprehensive concepts to delineate geomorphological units and structure types from remote sensing images, and infer about mechanical processes without necessarily measuring displacement, deformation or the applied forces directly (Melton 1959; Davis and Reynolds, 1996; Passchier and Trouw, 2005; Pollard and Fletcher, 2005). Surface discontinuities observed in rocks

41 and sediments have proven to be valuable indicators of the deformation history and stress pattern of the

42 slope. For landslide analysis, their observation and interpretation can contribute to a better understanding 43 of the controlling physical processes and help in the assessment of the related hazards (McCalpin, 1984;

44 Fleming and Johnson, 1989; Parise, 2003). In hard-rock slopes, the analysis of structural discontinuities 45 (faults, bedding planes, joints, fractures) allows to characterize potentially unstable areas (Hoek and Bray, 46 1981; Matheson, 1983; Priest, 1993; Selby, 1993; Günther et al., 2004; Jaboyedoff et al., 2004; Glenn et 47 al., 2006). In soft-rock slopes and sediments, the analysis of surface fissures may indicate the 48 development of future failures (Krauskopf et al., 1939; Shreve, 1966; Chowdhury and Zhang, 1991; 49 Abramson et al., 2001; Khattak et al., 2010) and is often considered as a geo-indicator of the activity stage 50 of a landslide. In sediments, the surface fissure characteristics also influence water infiltration and 51 drainage, which in turn affect the ground-water system and the kinematic response of slopes to 52 hydrological events (Malet et al., 2003; Malet et al., 2005b; van Asch et al., 2009). 
53 Maps of surface deformation features can be obtained by extensive field surveys either through the direct

54 visual observation of the topography (Fleming et al., 1999; Meisina, 2006) or through the indirect 55 measure of seismic wave propagation in tomography setups (Grandjean et al., 2011; Bièvre et al., 2012). 56 Relatively large fissures on landslides may also be discernible in Very-High-Resolution (VHR) 57 spaceborne images (Glenn et al., 2006; Youssef et al., 2009) but typically those structures reach widths in 58 the decimetre-range and at present only airborne photographs provide sufficient detail for their detection 59 in the centimetric range. Recent studies (Eisenbeiss, 2009; Niethammer et al., 2011a) have shown that 60 VHR images acquired from Unmanned Aerial Vehicles (UAVs) are cost-efficient data sources for the 61 monitoring of landslide surfaces with sub-decimetric image resolution. Especially small UAVs with 62 payloads below $5 \mathrm{~kg}$ and operating altitudes below $2000 \mathrm{~m}$ are expected to be employed much more 63 frequently in coming years (Frost \& Sullivan, 2007) though more specific regulations for their specific 64 operational use are being discussed at national and international levels (Prats et al., 2012; Watts et al., 65 2012).

66 Visual interpretation of VHR imagery is a classical method in geomorphology, but it remains subjective,

67 and rather impractical for repetitive observations or the inspection of large areas. An increasing number of 68 studies therefore targeted the development of automated techniques to extract relevant features from 69 imagery (Graham et al., 2010; Martha et al., 2010; Stumpf and Kerle, 2011). Although, the detection and 70 extraction of linear features is a fundamental operation in digital image processing (Quackenbush, 2004;

71 Mendonca and Campilho, 2006; Papari and Petkov, 2011), relatively few studies have explored the 72 application of automatic approaches for the mapping of geomorphological relevant linear features 73 (Baruch and Filin, 2011; Shruthi et al., 2011).

74 Considering the increasingly widespread availability of sub-decimetre resolution images from UAVs and 75 other airborne platforms, this study targeted the development of a semi-automatic image analysis 76 technique to support geomorphologists in the detection, mapping and characterization of landslide surface

77 fissures from VHR aerial images. In this context the term "semi-automatic" expresses that the technique 78 requires user input to be adapted for different image types and environmental settings. The developed 
method is based on a combination of Gaussian directional filters, mathematical morphology and object-

80 oriented image analysis (OOA) and was tested on a set of multi-temporal VHR images acquired at the

81 Super-Sauze landslide (Southeast French Alps). The obtained results were compared to manual mappings

82 carried out by experts combining image interpretation and field surveys.

\section{Types of surface fissure observed on landslides}

85 Detailed observations of landslide surface fissures were provided by Krauskopf et al. (1939) who adapted 86 analogies from structural geology for their interpretation and distinguished between strike-slip structures, 87 normal faults, graben structures and compression structures. Also Ter-Stephanian (1946) noticed the 88 mechanical significance of surface fissures and elaborated a classification scheme relating fissure 89 morphology and location within the landslide mass to corresponding mechanical processes. This included 90 a first-order differentiation between upper extension, side friction, central compression, and lower creep-

91 on cracks. Although some authors used similar classification schemes (Bombard, 1968), the adopted 92 terminology varies among different authors and affected lithologies (Fleming and Johnson, 1989; Cruden 93 and Varnes, 1996; Fleming et al., 1999; Walter et al., 2009) and the terms crack and fissure are often used 94 synonymously to refer to a variety of surface discontinuities.

95 Here, fissure is adopted as a generic term for open fractures on the topographic surface of a natural slope.

96 At first instance, transversal, longitudinal and diagonal fissures are distinguished according to their main

97 orientation axes relative to the dip of the slope. This terminology can be used ad hoc to classify fissures 98 solely based on geometric properties observed in the field or in an image. A more refined mechanical 99 classification such as provided in Ter-Stephanian (1946) will generally require considerations of the 100 fissure patterns, the involved material and the local geometry of the slip surface. The term crack is used in 101 this manuscript when referring to genetic processes described within classical fracture mechanics 102 (Anderson, 2005). It should be noted that the term crack is also often adopted to refer to shrinking103 swelling induced fractures (Malet et al., 2003) which are not the objective of this study. 
104 Classical fracture mechanics postulates tensile opening, sliding and tearing as the three basic modes for 105 crack propagation (Fig. 1a). The concept has been developed for brittle material but is also adopted to 106 explain fracturing of plastic materials at high deformation rates (Schulson and Duval, 2009). Surface

107 fissures may develop from a combination of all three modes, whereas in practice, considering the 108 relatively low tensile fracture toughness of most geomaterials (Backers, 2004; Ke et al., 2008; Schulson 109 and Duval, 2009), tensile fracturing can be expected to dominate the formation of fissures at the free 110 surfaces of a landslide. However, interpreting tension cracks as a direct indicator for a purely tensile stress 111 regime may often fall too short. In fact, tensile fracturing may also result from relaxation of tensile 112 stresses that originate from deformation induced by shearing and compression as well (Wang and Shrive, 113 1995). A mechanical interpretation and classification of the fissures must therefore consider the fissure 114 pattern, the material and the landslide geometry.

FIG. 1 SOMEWHERE HERE

119 Fig. 1b-d illustrates three typical fissure patterns that are frequently used as geoindicators of specific 120 deformation processes in the above-cited studies. One commonly observed example for such patterns is 121 the formation of en-echelon fissure arrays (Fig. 1c), often also termed Riedel shears (Riedel, 1929). They 122 accommodate tensile stress and shear stress typically resulting from shear in the bounding zone of blocks 123 moving with different displacement rates. Certain patterns such as arrays of transversal fissures (Fig. 1b) 124 are typically associated with tension in the steeper upper slopes, whereas fissures resulting from 125 compression and lateral extension (Fig. 1d) are more typically associated with gentler slopes in the transit 126 and accumulation zones of landsides (Sowers and Royster, 1978). For landslides with a complex 127 geometry, the position of those fissure patterns may however deviate considerably from this simple 128 scheme (Niethammer et al., 2011a). 
131 The Super-Sauze mudslide is an active slow-moving landslide located in the Barcelonnette Basin in the

132 Southern French Alps (Fig. 2) that developed in weathered black marls in the 1960s, and features highly

133 variable displacement rates (from $0.01 \mathrm{~m}^{-\mathrm{day}^{-1}}$ to $0.40 \mathrm{~m} \cdot \mathrm{day}^{-1}$ ) controlled by the local hydrological

134 conditions (Malet et al., 2005b). The landslide measures $950 \mathrm{~m}$ from the main scarp to the toe, and is up

135 to $150 \mathrm{~m}$ wide. The moving mass has a clay-rich matrix containing up to $30 \%$ coarse gravel as well as

136 larger boulders and blocks (Malet et al., 2005b). The surface displays the signs of deformation in the form

137 of ridges, bulges, lobes and fissures but also markers of surface erosion such as rills and small gullies.

138 Unlike surrounding stable areas the landslide surface is largely bare and only at a few locations,

139 especially at its toe, cushion plants form small vegetation patches. Fissure widths of 0.01-0.40 m, lengths

140 of more than $1.00 \mathrm{~m}$ and depths of up to $1.50 \mathrm{~m}$ (Espinosa, 2009) can be observed in the field (Fig. 4b).

141 During the last 15 years, the landslide has been investigated through numerous monitoring campaigns

142 including in-situ geophysical measurements, terrestrial and airborne LiDAR (Light-Detection and

143 Ranging) and the acquisition of VHR optical imagery. In the VHR airborne optical images, the fissures

144 can be recognized as dark curvilinear structures (Fig. 2c-e) as soon as their width approaches one pixel in

145 size. Previous studies (Malet, 2003; Niethammer et al., 2011a; Walter et al., 2012) already discussed

146 relationships between the observed fissure patterns (Fig. 2c-e) and strain resulting from a spatially

147 heterogeneous displacement field and interactions between moving mass and the stable bedrock.

148 However, a full reconstruction of the complex bedrock geometry that may allow for a more detailed

149 characterisation of the underlying deformation mechanisms has been completed only recently (Travelletti

150 and Malet, 2012).

151

152 FIG. 2 SOMEWHERE HERE

153 
155 Between April 2007 and October 2009, diverse imaging systems and airborne platforms were used to 156 acquire VHR images of the landslide at five different dates (Fig. 3). In July 2008, October 2008, and 157 October 2009, a low-cost UAV system equipped with compact camera was operated at flight heights 158 between $100 \mathrm{~m}$ and $250 \mathrm{~m}$ yielding images of the surface with a ground resolution between $0.03 \mathrm{~m}$ and $1590.10 \mathrm{~m}$. The individual images were corrected for barrel lens distortion, rectified according to ground 160 control points (GCPs) measured with differential GPS (DGPS), and finally merged into one large 161 orthomosaic. Further details on the image acquisition and processing were provided by Niethammer et al.

$162(2010 ; 2011 b)$ who quantified the residual positional error $(x-y)$ for the October 2008 images with $1630.5 \pm 0.57 \mathrm{~m}$ within the boundaries of the sliding area. The UAV images for July 2008 and October 2009 164 are expected to provide better positional accuracies because they were orthorectified using elevation 165 models that were generated from a photogrammetric analysis of the images.

166 During the airborne LiDAR surveys (see § 3.2) of, respectively May 2007 and July 2009, two 167 orthomosaics of optical images with full coverage of the landslide were recorded using medium format 168 cameras (Fig. 3) mounted on, respectively an airplane and a helicopter. The surveys used fully integrated 169 systems for direct georeferencing and orthorectification with LiDAR surface models (see $\S 3.2$ ), which in 170 general provide sub-decimetre positional accuracy in the x-y plane (Vallet, 2007).

171 For the study presented here, additionally 60 homologous tie points on stable areas were manually 172 selected in the available images and showed a mean relative alignment error of $0.76 \pm 0.82 \mathrm{~m}$ among the 173 different acquisitions.

174 Further details on the adopted camera systems and the resolutions of the images resulting from the five 175 surveys are summarized in Fig. 3. The figure also illustrates the considerable radiometric differences 176 among the five images originating from illumination changes, seasonal variations and the distinct 177 characteristics of the sensors. The scenes for May 2007, October 2008 and October 2009 were acquired 178 under cloudy conditions with diffuse sky radiation and consequently show a more homogenous 179 illumination of the surface. The scenes for July 2008 and July 2009 in contrast were recorded under sunny 
sky yielding strong contrast and many cast shadows. The latter are more prominent in the image for July

1812008 which was recorded in the morning hours, at a relatively low sun angle. Available methods for

182 absolute and relative radiometric correction can be employed for the radiometric alignment of satellite

183 images (Hong and Zhang, 2008; Vicente-Serrano et al., 2008) but, to the best of our knowledge, no

184 approach exists to accurately align the radiometry of sub-decimetre images from different sensors, with

185 substantial changes in illumination, a complex topography and changing surface characteristics. Initial

186 test using histogram-matching, linear-regression (Schott et al., 1988) and iteratively re-weighted

187 regression (Canty and Nielsen, 2008) did not provide satisfactory results. Consequently no radiometric

188 normalization was performed and the image analysis technique was designed and tested with radiometric

189 diverse imagery.

190 In order to calibrate adjustable parameters of the detection algorithm to the targeted fissures and the 191 variable scene characteristics, the processing was first tested on a subset of the terrain covering $19214.000 \mathrm{~m}^{2}$ in the central part of the landslide (Fig. 2a, Fig. 3). This section was characterized by different 193 fissure patterns and recorded during all surveys (including July 2008 and October 2009 which did not 194 yield full coverage of the surface). Subsequently, the developed workflow was applied on the full scenes 195 for a comprehensive mapping and analysis of the fissure distribution. Corresponding results for the full 196 extent of the Super-Sauze landslide and their mechanical significance are discussed in section $\S 5.2$.

FIG. 3 SOMEWHERE HERE

199

$200 \quad 3.2 \quad$ LiDAR DTM

201 Two airborne LiDAR surveys were conducted in May 2007 and July 2009, respectively. The first survey 202 used a Riegl LMS-Q560 laser scanner mounted on an airplane flying $600 \mathrm{~m}$ above the ground and 203 resulted in a mean point density of 0.9 pts. $\mathrm{m}^{-2}$ after vegetation filtering. The residual 3D positional error 204 of the ground points was quantified as $0.12 \mathrm{~m}$. The second survey was conducted with a Riegl Q240i laser 205 scanner mounted on a helicopter and after vegetation filtering resulted in a mean point cloud density of 
207 with a pixel size of $0.5 \mathrm{~m}$ were interpolated from the respective point clouds using Delaunay 208 triangulation. The resulting surface was then adopted for the extraction of the principal hydrological 209 drainage lines.

\section{$2113.3 \quad$ Reference datasets: expert maps of surface fissures}

212 Reference mappings of the fissure characteristics (type, distribution) were elaborated by an expert 213 geomorphologist familiar with the study site. The fissures were first identified on-site during a field 214 survey carried out in October 2009 at the same time as the acquisition of the UAV images. The position 215 of the fissures was mapped using a dGPS survey and terrestrial photographs. Then image interpretation 216 rules were defined to identify and digitize the fissures on the images as polyline vectors using a $2 \mathrm{D}$ view 217 and at a scale of 1:250. The image interpretation rules were then applied to the four other images in order 218 to elaborate an expert fissure map for each date. The resulting five maps were adopted as a reference to 219 assess the performance of the semi-automatic method.

\section{Image processing methods}

222 While first generic edge detection operators were already proposed in the 1980s (Marr and Hildreth, 223 1980; Canny, 1986), the extraction of linear features from imagery remains a challenging task in many 224 disciplines such as medical research (Mendonca and Campilho, 2006), earth science (Shao et al., 2011; 225 Shruthi et al., 2011) or signal processing (Lampert and O'Keefe, 2011). For our focus, the specific 226 challenges posed for an automation of fissure detection can be summarized as follows:

227 - The approach should be scalable to apply for variable fissure sizes and image resolutions, and as 228 insensitive as possible to variable radiometric image characteristics;

229 - The technique should not respond to edges but enable the detection of dark curvilinear structures that 230 may be oriented at any direction. Classical techniques such as Sobel operator and the Canny detectors 
(González and Woods, 2008) have been designed specifically for edge detection and are not directly

232 applicable;

233 - The complex micro-topography, the presence of rock blocks and gravels as well as small patches of

234 vegetation yield highly textured images. Consequently, the approach should enable to smooth out

235 spurious signals from the noisy background while still retaining small partially disconnected linear

236 features of interest. Contextual scene information should be taken into account to resolve ambiguities

237 of the local features.

238 Considering these challenges, a processing workflow including three main stages was developed. Firstly,

239 a set of scalable Gaussian filters is applied to detect fissure candidates and suppress responses at edges.

240 Secondly, a set of morphological filters is used to close small gaps along the extracted candidates.

241 Thirdly, an object-oriented procedure is followed to eliminate some of the false positives exploiting

242 higher-level scene information with contextual rules.

244 FIG. 4 SOMEWHERE HERE

2464.1 Stage 1: Extraction of fissure candidates using a Gaussian matched filtering algorithm

247 A particularly well-studied example for the detection of dark curvilinear structures is the extraction of 248 dark blood vessels in photographs of the human retina. Based on the observation that the cross-profiles of 249 the vessels resembles a Gaussian distribution, Chaudhuri et al. (1989) proposed the use of a matched filter 250 (MF) that is essentially a Gaussian convolution kernel subtracted by its own mean value. As illustrated in

251 Fig. 4a, the cross-sections of surface fissures can be approximated with a Gaussian distribution and an

252 MF scaled to the size of the fissure will give a peak response when crossing the fissure at an angle of 253 approximately $90^{\circ}$. Because the MF still yields errors such as false detections at step edges (Fig. 5a,c) 254 numerous extensions (Hoover et al., 2000; Sofka and Stewart, 2006) and alternative approaches 255 (Mendonca and Campilho, 2006; Soares et al., 2006) have been developed. Recently, Zhang et al. (2010) 256 proposed modification to the original MF filtering approach integrating a first order derivative of a 
257 Gaussian function (FDOG) to locally adapt the thresholds separating dark line from non-target features.

258 Compared to other state-of-the-art algorithms their approach provided competitive accuracies while being 259 a computationally efficient and hence easier to apply on the large images resulting from VHR remote 260 sensing.

261 For this study, a similar approach was implemented in ENVI-IDL 4.8 (ITT Visual Information Solutions).

262 The algorithm and its parameterization are detailed below.

267 The MF is a two dimensional kernel defined in the x-direction by an inverted Gaussian profile (Fig. 5b), 268 and in the y-direction by replicates of the same profile (Fig. 5d). It may be denoted as:

272 where $\sigma$ denotes the standard deviation of the Gaussian functions and relates to the width of the targeted 273 feature. To centre the kernel on zero, it is subtracted by its own mean $m$. The extent of the kernel in the $\mathrm{x}-$ 274 direction is typically constrained to $3 \sigma$, whereas $L$ defines the extent of the kernel in the y-direction and 275 can be related to the length of the fissures. Because the matched filter still yields false responses at dark 276 and bright step edges (Fig. 5c) Zhang et al. (2010) proposed to use the response of the FDOG to locally 277 adjust the thresholds which are applied to classify the MF response into fissure and non-fissure structures. 278 In analogy to Eq. 1, the first order derivative filter may be denoted as: 
Fig. $5 \mathrm{f}$ illustrates that the FDOG responds with a single peak to edges but with a zero crossing at the centre of the idealized fissure. A simple mean filter can be applied to broaden the zero crossing into a

284 plateau covering the whole width of the fissure (Fig. 5f). Subtracting the smoothed FDOG response from 285 the MF response will attenuate the signal at edges while at the position of the fissure the full response is 286 retained (Fig. 5h).

287 Since the orientation of the fissures is a priori unknown, multiple rotated versions of the Gaussian filters 288 are applied on the image and for each pixel only the maximum response value is retained. This 289 corresponds to finding the angle $\theta_{\max (x, y)}$ which maximizes the filter response at a given position in the 290 image $I_{(x, y)}$ using Eq. 3:

294 where $\otimes$ denotes the convolution operator and $\theta$ the orientation of the MF.

295 The calculation of the maximum response image $R$ can then be obtained with Eq. 4: response image $D$ can be derived by Eq. 5: fissures. 
While Zhang et al. (2010) used a very broad mean filter with a fixed size, we suggest to use a kernel size

308 that matches the width of the Gaussian kernel $(6 \sigma)$ and is thereby related to the width of the targeted

309 features (Fig. 5a,f). In contrast to early studies where the FDOG response was used to locally adapt the

310 threshold (Zhang et al., 2010) the final response image $\bar{R}$ is obtained by subtracting the FDOG from the

311 GMF response using Eq. 6:

312

$313 \overline{R_{(x, y)}}=R_{(x, y)}-C t * D_{(x, y)}$

Eq. 6

314

315 where $C t$ denotes a user defined trade off parameter to adjust the sensitivity of the detection with typical

316 range of values between 3 and 4 . A threshold $T$ is defined by Eq. 7:

$318 T=\mu_{\bar{R}}+2 \sigma_{\bar{R}}$

Eq. 7

where $\mu_{\bar{R}}$ is the mean of the response image $\overline{\mathrm{R}}$ and $\sigma_{\bar{R}}$.

322 A binary fissure candidate map $F_{\text {map }}$ is obtained by applying the threshold $\mathrm{T}$ on the response image $\overline{\mathrm{R}}$ 323 using Eq. 8:

$\overline{R_{(x, y)}} \geq T_{(x, y)}: F_{\text {map }}=1 \quad$ and $\quad \overline{R_{(x, y)}}<T_{(x, y)}: F_{\text {map }}=0$

Eq. 8

327 The thresholding after subtraction of the FDOG response was found to provide a generally more robust

328 attenuation of undesired edge responses than the technique previously applied by Zhang et al. (2010).

329 In summary, the user needs to specify four simple parameters, namely (1) the scale of the filter kernels in 330 terms of $\sigma,(2)$ the length $L$ of the kernel, (3) the constant $C t$ of the thresholding sensitivity and (4) the 331 number of orientations $n_{\theta}$ at which the filters are calculated. In this study, $\mathrm{n}_{\theta}$ was kept constant at 36 for 
332 all experiments, whereas, if computational time becomes an issue, the angular resolution may be reduced

333 to 12 steps without major losses of accuracy. To determine $\sigma$ a tool was created,which allows drawing

334 profiles on the image and automatically estimates the fitting Gaussian function (Fig. 4). Cross-profiles of

335 the smallest fissures visible in the image with the coarsest resolution $\left(0.1 \mathrm{~m}\right.$. pixel $^{-1}$ resolution $)$ were best

336 fitted by Gaussian curves with $\sigma \approx 0.6$. To ensure a homogenous scale of the detected features among all

337 images, the kernel can be scaled by changing $\sigma$ relative to the image resolution. If, for instance, the image

338 resolution is increased to 0.08 m.pixel ${ }^{-1}$, a value of $\sigma \approx 0.75$ yields a kernel with the same physical size

339 (Table 1). The same applies for the filter length $L$ which was estimated as $1 \mathrm{~m}$ corresponding to the

340 typical minimum length of the fissures. Resampling of the images can thereby be avoided. In our

341 experience, $\sigma$ establishes the lower bound for the width of the targeted features, whereas the filters still

342 remain sensitive to features which are up to 5 times larger. For the choice of $\sigma$ it is also helpful to note

343 that the discrete kernel cannot represent FDOG functions with $\sigma \leq 0.5$.

344 To assess the sensitivity of the parameters and to determine a suitable threshold parameter $C t$, a 345 sensitivity analysis was carried out on a subset of the October 2008 image. Based on a visual assessment, 346 values of $L=1 \mathrm{~m}$ and $\sigma=0.75$ were found suitable for the detection of the fine fissure structures. The 347 preliminary analysis also showed that increasing the parameters $L$ and $\sigma$ directs the detection towards 348 more elongated and broader features, whereas in general the sensitivity of those parameters is rather low 349 compared to the influence of the threshold $C t$. Values of $C t=\{0.0,1.0,2.0,3.0,4.0\}$ were tested and 350 based on a visual assessment of the outputs a value of $C t=3$ was established for an optimal trade-off 351 between detection rate and the amount of false positives. The final parameter set is summarized in Table 3521.

354 TABLE 1 SOMEWHERE HERE 
357 The highly textured surface of the landslide constitutes a noisy background that affects the detection 358 especially at section where the fissures are very thin or partially occluded. While a human operator can 359 easily interpolate broken lines through perceptual grouping (Metzger, 1975), this needs special attention

360 for a semi-automated mapping technique.

361 To close small gaps between broken line segments of the detected candidates, a hit-or-miss transform 362 algorithm (Serra, 1982) was used. The transform assigns a value of 1 to each pixel whose local 363 neighbourhood fulfils the criteria defined by hit- and miss structures (Fig. 6a), also known as structuring 364 elements. They were defined to address all plausible 3-by-3 neighbourhoods representing small gaps in 365 the detection starting from four prototype hit-structures shown in Fig. 6b. The respective miss-structures 366 (Fig. 6c) are typically derived by simply inverting the prototype hit-structures, and both elements were 367 rotated (Fig. 6d) to test for a total number of 24 possible neighbourhood arrangements. Exceptional cases 368 were thereby the structuring elements for closing directly diagonal gaps, where an extended 369 neighbourhood was used for the hit-and miss structures (Fig. 6b, c) to prevent connections of lines 370 running parallel to each other.

374 The connectivity of the line segments was also particularly important for the subsequent object-oriented 375 post-processing, where objects constitute from pixels groups connected in a Von Neumann 376 neighbourhood (4 adjacent pixels at each side), and small isolated objects could be disregarded as noise.

\section{$378 \quad 4.3 \quad$ Stage 3: Object-oriented analysis for false positive removal}

379 Due to visually similar objects, such as linear erosion features (rills, small gullies) and elongated shadows 380 induced by the micro-topography, the fissure candidates resulting from the described filtering routine may 381 still comprise numerous false positive detections. While a human interpreter can differentiate most of the 
false positives assessing the geospatial context of the scene, the efficient use of such information with automated systems is a challenge for object-oriented image analysis. To exploit the contextual scene

384 information for an automatized refinement of the extracted fissure candidate maps, an object-oriented 385 routine that integrates spatial reasoning into an explicit form was elaborated and implemented using 386 eCognition 8.64 (Trimble, 2011). The elaborated routine included the following steps:

387 1) The ratio of shadow around the detections is evaluated and candidates with a ratio of shadow pixels in their smallest enclosing circle above $33 \%$ are regarded as false detections induced by shadings of the micro-topography. This ratio threshold was determined empirically through visual inspection of the candidate fissures, and selected to capture elongated false detections with one side lying fully in shaded zones. The threshold for shadow can thereby be adjusted according to the illumination conditions and the dynamic range of the image (Table 2).

2) Further false detections may result from vegetation which typically shows a lower reflectance in the green and red channel compared to the blue. The blue ratio in the sum of all channels is consequently typically below one third for vegetated areas. The suitable value varies slightly with the illumination conditions and the season, and Otsu's method (Otsu, 1979) was employed to automatically adapt to such changes. Through an iterative testing of all possible values, Otsu's method determines threshold value that maximizes variance between two classes in an image. Hence, constraining the search space to all pixels with a ratio blue below 33\%, the algorithm was used to determine the thresholds that maximize the contrast between vegetation and the background (Fig. 7). Fissure candidates covered by the resulting vegetation class, or having a relative border length larger than 0.15 , were subsequently removed.

3) Another class of frequent false detections resulted from linear objects such as rills, gullies and nearly vertical steps at the landslide flanks, which may locally obtain similar characteristics as the targeted 
fissures. To test for the presence of larger linear features and evaluate their relationship with fissure candidates, a strategy to suppress additional false positives was required. For the mapping of the larger linear elements two sources were adopted. First drainage lines were extracted from the LiDAR DTMs using hydrological standard tools (Tarboton et al., 1991) and enlarged with a surrounding buffer of $0.5 \mathrm{~m}$. A second approach was to repeat the Gaussian filtering with the parameter set indicated in Table 1, but with a two times increased scale $\sigma$ and a 5 times coarser image resolution (resampled with bilinear interpolation). This is equivalent to a search with a 10 times larger scale providing a sufficiently large scale difference to assure that none of the detected linear features would correspond to fissures. The linear objects extracted with both approaches were virtually overlaid with the fissure candidates, and the difference of the orientations of their respective centre lines was adopted as criteria to evaluate if the fissure candidate was in fact part of a larger linear object or constitutes an independent structure (Fig. 8). Image-based measurements of the angular offset of the fissured indicated a minimum offset of about $\pm 13^{\circ}$. Considering that the lowest effective friction angle values measured for the landslide material are $\alpha^{\prime}=26^{\circ}$ (Malet et al., 2005a), the thresholds are consistent with the orientation of $\alpha^{\prime} / 2$ that the Coulomb criterion predicts for the

425 FIG. 8 SOMEWHERE HERE

4) A last filtering step was implemented by removing all candidates with length not longer than $0.4 \mathrm{~m}$ and an area smaller than $0.1 \mathrm{~m}^{2}$. Finally all fissure candidates falling in areas with a fissure class density lower than $1 \%$ in a surrounding neighbourhood of $10 \mathrm{~m}^{2}$ were considered as noise and also removed. 
431 Table 2 displays that most adopted thresholds were kept the same among all the images and only the 432 classification rule for the shadow areas was adapted in order to compensate radiometric differences in the 433 input images.

434

435 TABLE 2 SOMEWHERE HERE

436

4375 Results

438

$439 \quad 5.1 \quad$ Comparison with multi-temporal manual mappings

440 The primary output of the developed processing routine is a map of the detected fissures represented by 441 polygons. Applying a Delaunay triangulation that extracts the skeleton of those polygons (Trimble, 2011), 442 a 2D line representation, which enables a more immediate comparison with expert mappings, can be 443 obtained.

FIG. 9 SOMEWHERE HERE

447 Fig. 9 displays an example of comparison between an expert map and the result of the semi-automatic 448 detection. A first visual assessment of the obtained maps suggested better agreement of the fissure 449 patterns in areas with high contrast and low texture (Fig. 9a), whereas false positives and false negatives 450 concentrated in sections with low contrast and increased surface texture (Fig. 9b).

451 For a quantitative assessment of the mapping accuracy the obtained results were compared with the expert 452 mappings in the central part of the landslide (Fig. 9c) at all five dates. While several accuracy measures 453 for geographic line datasets have been already proposed, there is still no consensus about one generally 454 applicable technique and the metrics should be selected according to the problem at hand (Ariza-López 455 and Mozas-Calvache, 2012). Here, we focused on three crucial aspects of the map accuracy that may have 
456 direct implications for their further use, namely the size of the affected (e.g. fissured) area, the length and

457 density of the fissures, and their orientation.

\subsubsection{Size of the fissured area}

460 Tveite and Langaas (1999) suggested an accuracy measure for line datasets based on repeated buffering 461 and overlay operations of detected and reference line datasets. A similar strategy was adopted in this 462 study by repeatedly calculating true positive and false positives rates from two raster representing the 463 detections and the expert mapping at increasingly coarser resolutions. Raster were calculated at $10 \mathrm{~cm}$ 464 steps for resolutions between $0.10 \mathrm{~m}$ and $1.00 \mathrm{~m}$, and each pixel was assigned as fissured or non-fissured 465 area according to the presence or absence of a fissure in the detections and the reference map, 466 respectively. The resulting Receiver Operating Characteristics (ROC) plots are presented (Fig. 10). The 467 analysis showed a correspondence with the expert maps at true positive rates typically above $40 \%$ and up 468 to $65 \%$. The false positive rates were below $5 \%$ except for the scenes recorded with full sunlight where 469 false positive rates up to $9 \%$ could be observed (Fig. 10).

471 FIG. 10 SOMEWHERE HERE

\section{$473 \quad$ 5.1.2 Fissure length and density}

474 Hydrological models that integrate the influence of surface fissures on infiltration and preferential flow 475 have demonstrated that the fraction of fissures per unit area is an important parameter with considerable 476 influence on the modelled water storage (Malet et al., 2005b; Krzeminska et al., 2011). Such models are 477 typically generated at slope scale with grid resolutions below $10 \mathrm{~m}$. To assess the accuracy of the 478 extracted maps with respect to this potential application, the fissure density was calculated as the line 479 length in circular sliding windows with diameters between 2 and $10 \mathrm{~m}$, and compared among automated 480 detection and expert mappings. 
The regression plots in Fig. 11 illustrate the correlation of the fissure density estimates with a $5 \mathrm{~m}$ circular sliding window yielding coefficient of determination $\left(\mathrm{R}^{2}\right)$ typically above 0.5 . The regression analysis further indicated generally higher densities resulting from the semi-automatic detection originating from false positive detections but also from a stronger generalization of the fissure line drawings within the expert mapping. Exceptions from this general trend are the results obtained from the image of July 2008 which was recorded at a low sun incidence angle leading to a relatively low $R_{5 m}^{2}=0.36$. The bar plots in Fig. 11display the generally higher $\mathrm{R}^{2}$ values at increasing resolutions of the density raster. This is a well491 known effect of spatial aggregation on correlation statistics (Gotway and Young, 2002) but also reflects 492 the contrast between stronger discrepancies of local details and a better correspondence of the global 493 fissure pattern pictured in the respective maps. The highest correlation was observed among the mappings 494 for May 2007 with $R_{10 m}^{2}=0.88$ indicating that the lower resolution of the corresponding input image 495 was not an important factor for the accuracy of the detection.

\subsubsection{Fissure orientation}

498 As outlined in the introductory section, different fissure patterns may signal respective mechanical 499 processes and statistics of the principal fracture orientation often allow to estimate the directions of the 500 principal stresses (Pollard and Fletcher, 2005). The fissure orientations were quantified as a third factor to 501 assess the accuracy of the extracted maps using rose diagrams frequently employed for the analysis and 502 interpretation of two dimensional orientation data (Jammalamadaka and SenGupta, 2001). Rose diagrams 503 with a bin width of $10^{\circ}$ were computed on a $10 \mathrm{~m}$ regular grid for the semi-automatic detections and the 504 expert mappings at all five dates. Considering the length and direction of each bin expressed as a respective vector the preferred fissure orientation within a grid cell can be calculated by summing the 
semi-automatic detection, the Mean Absolute Error (MAE) of the mean orientations provides a

508 quantitative measure for the orientation accuracy.

509 The rose diagrams plots and error statistics in Fig. 12 depict MAEs between $9.7^{\circ}$ and $22.5^{\circ}$ for the five 510 dates. The detections on the three scenes recorded under cloudy sky resulted in MAE not larger than

$51110.7^{\circ}$, whereas the error rate clearly exceeded $20^{\circ}$ with the scenes of July 2008 and 2009 recorded with

512 full sunlight at the surface. The lower orientation accuracies are largely consistent with the relatively low

513 accuracies in terms of area (see $\S 5.1 .1$ ) and density (see $\S 5.1 .2$ ) resulting from the detection at the latter

514 two dates.

FIG. 12 SOMEWHERE HERE

$519 \quad 5.2 \quad$ Fissure patterns as possible geoindicators of deformation processes

520 For a comprehensive interpretation of the detected fissure patterns at the scale of the entire slope, the 521 scenes of May 2007, October 2008 and July 2009 offering a full coverage of the landslide, have been 522 analysed. However, considering the relatively low detection accuracy on the sunlit images of July 2009, 523 the interpretation was focused essentially on the scenes of 2007 and 2008 spanning also over a period 524 with displacement rates significantly above the average annual rates (Travelletti, 2011).

525 Comparing the detection results of May 2007 (Fig. 13a) and October 2008 (Fig. 13b), a significant 526 increase in the abundance of fissures could be noted for the entire landslide. This can be attributed to a

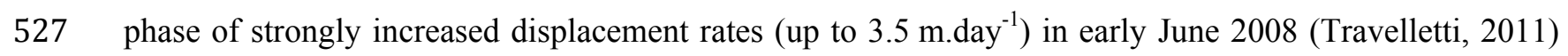
528 preceding the UAV survey in October 2008. Though, in October 2008, the displacement rates already 529 consolidated again at average rates between 0.01 and 0.03 m.day $^{-1}$, most of the fissures induced in June 530 were preserved and evolved at the surface until October. This view is supported by the results obtained 531 for the test area with the five scenes (Fig. 10, Fig. 11) picturing rather a transient evolution than a 532 complete reorganization of the fissure patterns. Despite partially strong disagreement in the absolute 
measured fissure density, both expert maps and semi-automatic mapping showed an increase in fissure

534 density after May 2007, with higher values in October 2008 (Fig. 11) than directly after the peak

535 displacement in spring. Pluviometric records for the area in 2008 show relatively dry summer season with

536 cumulative rainfall of $110 \mathrm{~mm}$ for the month of July, August and September, suggesting that the

537 increased fissure density in October is partially caused by an increased brittleness of the upper soil layer

538 that dried out during summer.

539 Besides the general increase in the amount of fissures, it is intriguing to observe that at several local plots,

540 similar fissure patterns can be observed at approximately the same positions through time (Fig. 12, Fig.

541 13a,b), despite maximal displacements of up to $55 \mathrm{~m}$ between October 2008 and October 2009

542 (Niethammer et al., 2011a). This indicates the recurrent continuous in-situ formation where the fissures

543 provide a close representation of the local strain field, similar as observed for the evolution of glacier

544 crevasses (Harper et al., 1998).

545 Previous studies (Malet, 2003; Niethammer et al., 2011a; Walter et al., 2012) already observed close

546 relationships between the occurrence of fissures and the geometry of the stable bedrock at the Super-

547 Sauze landslide. They also noted a general contrast between higher water content and rather ductile

548 behaviour in the lower subsurface $(<1 \mathrm{~m})$ and typically lower water content of the topsoil yielding more

549 brittle behaviour at the surface. The surface fissures can therefore be understood as the response to

550 stresses induced in the topsoil through coupling with ductile strain in the deeper subsurface. A similar

551 model was already described by Fleming and Johnson (1989) and adopted as a basis to qualitatively

552 estimate the patterns of flow and stresses from a joint-interpretation (Fig. 13) of the detected fissure

553 patterns and a geometrical model of the stable bedrock (Travelletti and Malet, 2012).

554 Considering the bedrock geometry and a formation of the open fissures normal to the direction of the least

555 compressive stress (Pollard and Fletcher, 2005), three different flow field patterns leading to the fissure

556 formation at the Super-Sauze landslide can be suggested. First, lateral shear at external and internal

557 landslide boundaries aligned with the general flow field leads to the formation of diagonal shear fissure

558 arrays (Fig. 13e). Second, longitudinal compressive and tensile strain related to abrupt changes in the 
559 slope of the sliding surface induces tensile stresses at the surface that results in transversal fissure arrays

560 (Fig. 13c). Third, divergence of the flow field over topographic ridges and at the outlets of confining

561 topographic channels induces lateral extension and tensile stresses resulting in longitudinal fissure arrays

562 (Fig. 13d). At several locations, those processes overlap and lead to the formation of mixed structures

563 such as a radial fissure patterns displayed in Fig. 4 and Fig. 13c, resulting from lateral shear and

564 longitudinal strain, and from local divergent stress field, respectively.

566 FIG. 13 SOMEWHERE HERE

\section{Discussion}

569 Deformation patterns at the surface of landslides are important indicators for the mechanical processes, 570 whereas the elaboration of detailed maps of such features remains a challenging and time-consuming task.

571 While Sowers and Royster (1978) still argued that aerial photographs do not reach sufficient resolution

572 for such mappings, modern digital sensors and new aerial platforms such as UAVs today provide the

573 necessary level of detail. Furthermore, this study demonstrated the possible use of a semi-automatic

574 image processing chain for the extraction of surface fissure maps.

575 The accuracy of the method was assessed by comparisons with expert maps and demonstrated 576 heterogeneous areal accuracies with true positive rates of up to $65 \%$ and false positive rates generally 577 below $10 \%$. Also, the orientation accuracy showed a variable quality of the resulting maps with mean 578 deviations between $9.7^{\circ}$ and $22.5^{\circ}$. The fissure densities derived from both maps have significant 579 correlations $\left(\mathrm{R}^{2}\right.$ between $\left.0.36-0.78\right)$, whereas the semi-automatic detections yield typically higher 580 estimates. Interestingly, this difference is more pronounced with the images of 2009 (Fig. 10) reflecting 581 the contrast between increased semi-automatic detection rates at higher resolutions and the fixed scale of 582 the expert mapping. Contrariwise, the best agreement among detection and expert maps was measured for 583 the scene of May 2007 showing that the lower resolution does not necessarily yield lower accuracies. 584 Generally lower accuracies were observed for the scenes recorded with full sunlight at the surface in July 
2008 and 2009 and the worst results were obtained for July 2008 when images were recorded at a

586 relatively low sun incidence angle. Since the direct sunlight induces shading that affects the local contrast 587 and global image normalization methods cannot alleviate this problem and image acquisition with diffuse 588 skylight appears to be the generally better option.

589 In the initial stage of the processing chain, a low-level linear feature detector is used. Similar techniques 590 yield competitive results in medical image analysis (Zhang et al., 2010), whereas the accuracies achieved 591 with aerial images in this study are still significantly lower. This must be attributed to the generally higher 592 complexity of outdoor scenes and at the moment still requires additional steps and parameters to take the 593 contextual scene information into account. The use of an OOA heuristic-based post-processing technique 594 proofed useful for the removal of false positives and helped to objectify the image analysis by transferring 595 expert knowledge in an explicit form. The analysis still relies on a number of fixed thresholds which may 596 hinder an easy transfer of the entire processing chain to a different geographic area. This concerns 597 especially parameters that require knowledge of the local processes (e.g. minimum fissure length, 598 effective friction angle) while thresholds that can be determined directly from the image (e.g. shadows, 599 vegetation) may be adjusted more effortless.

600 The development of surface fissures precedes and accompanies especially slow- and very slow-moving 601 landslides (Cruden and Varnes, 1996) making the developed technique particularly applicable to such 602 types of landslides and to potentially unstable slopes. However, the spatial resolution of the acquired 603 images must at least match, or should ideally exceed, the width of the targeted fissures, and the vegetation 604 must be sufficiently sparse to permit direct view on the bare ground. The results of this study 605 demonstrated that if those requirements are met, the obtained fissure maps can already provide sufficient 606 accuracy to infer the landslide dynamics and mechanical processes (see $\S 5.2$.) at the slope scale. Density 607 maps from both semi-automatic and expert mappings show a strong spatial and temporal variability of the 608 fissure abundance pointing toward important local and temporal contrasts in the infiltration capacity 609 which may need considerations in the design of hydro-mechanical models. An analysis of the evolution 610 and mechanics of individual fissures will however require higher temporal resolution and terrestrial 
611 cameras have recently been installed at the surface of the landslide to record imagery for further research

612 in this direction. It would also be desirable to test the developed technique for the investigation of other

613 landslides with different characteristics in order to validate a more general applicability of the approach

614 and the mechanical interpretation of the observed fissure dynamics.

615 The OOA heuristics already considers multi-scale information to some degree (see $\S 4.33$ ), whereas for

616 further methodological improvements an explicit integration of an automatic scale selection technique at

617 the low-level filtering stage appears as a promising approach to further reduce heuristics and tuneable

618 parameters (Stumpf et al., 2012). The first and second stages of the proposed method are generic for the

619 detection of dark linear features and could in principle also be applied to detect other geomorphological

620 and geological structures with similar characteristics. The proposed technique might be of interest for the

621 mapping of erosion gullies (Shruthi et al., 2011), geological lineaments (Mallast et al., 2011), ice-glacier

622 crevasses (Vaughan, 1993) or tectonically induced fractures (Allmendinger and González, 2010),

623 sufficiently larger to be depicted in sub-metre satellite images.

624 Considering the intrinsic disagreement in expert mappings of linear features, especially in the inter- and 625 extrapolation of lines (Sander et al., 1997), further studies should also include an assessment of the 626 uncertainties of reference maps since their quality can strongly bias the evaluation of different alternative 627 approaches (Lampert et al., submitted).

\section{Conclusions}

630 This study developed an image processing chain to extract surface fissures from heterogeneous sets of

631 VHR aerial images and tested the approach with a challenging multi-temporal set of images recorded at

632 the Super-Sauze landslide for five different dates. The first two stages of the developed workflow 633 combine families of Gaussian matched filters and morphological filters and are followed by an object634 oriented analysis to reduce the amount of false positive detection using contextual information and 635 auxiliary topographic information. The detection results can be represented in raster maps or optional by 636 centre skeleton lines. 
637 Under homogenous illumination conditions a comparison of the results with expert mapping 638 demonstrated detection rates of up to $65 \%$ and orientation errors below $10^{\circ}$. Contrary, the technique is 639 relatively sensitive to shading effects at full sunlight and prone to errors especially at low sun incidence 640 angle.

641 A joint-interpretation of obtained fissure maps and of a 3D geometrical model of the stable bedrock 642 demonstrated their complementary use for a better understanding of the geomorphological and 643 geomechanical processes, such that the detected fissure pattern may be used for first approximation for 644 mechanical processes in the recent deformation history of a slope.

645 Possible directions for further research are the reduction of tuneable parameters and a more immediate 646 exploitation of multi-scale information, as well as an adaption of the technique to other linear features 647 with geomorphological and geological relevance.

\section{Acknowledgements}

651 The work was supported by the project SafeLand "Living with landslide risk in Europe: assessment, 652 effects of global change, and risk management strategies" (Grant Agreement No. 226479) funded by the $6537^{\text {th }}$ Framework Programme of the European Commission, the project SISCA 'Système Intégré de 654 Surveillance de Crises de Glissements de Terrain' funded by the French Research Agency (Contract ANR 655 Risk-Nat, 2009-2012), the project FOSTER 'Spatio-temporal data mining: application to the 656 understanding and monitoring of soil erosion' funded by the French Research Agency (Contract ANR 657 Cosinus, 2011-2013), and the project Grosshang "Coupling of Flow and Deformation Processes for 658 Modeling the Movement of Natural Slopes" funded by the Deutsche Forschungsgemeinschaft (DFG). The 659 authors would like to acknowledge Alexandre Mathieu (University of Strasbourg) for his assistance in the 660 field and for the expert mapping of the different fissure patterns, and Julien Travelletti for discussion on 661 the recent dynamics of the landslide. The IDL code implementing the first two detection stages and the 662 eCognition rule set implementing the object-oriented analysis are available on demand. 


\section{References}

Abramson, L.W., Lee, T.S., Sharma, S., Boyce, G.M., 2001. Slope stability and stabilization methods, 2nd Edition. Wiley.

Allmendinger, R.W., González, G., 2010. Invited review paper: Neogene to Quaternary tectonics of the coastal Cordillera, northern Chile. Tectonophysics 495, 93-110.

Anderson, T.L., 2005 Fracture Mechanics: Fundamentals and Applications, 3rd Edition. Taylor \& Francis.

672 Ariza-López, F., Mozas-Calvache, A., 2012. Comparison of four line-based positional assessment methods by means of synthetic data. GeoInformatica 16, 221-243.

674 Backers, T., 2004. Fracture Toughness Determination and Micromechanics of Rock Under Mode I and Mode II Loading. PhD, Universität Potsdam, Potsdam.

Baruch, A., Filin, S., 2011. Detection of gullies in roughly textured terrain using airborne laser scanning data. ISPRS Journal of Photogrammetry and Remote Sensing 66, 564-578.

Bièvre, G., Jongmans, D., Winiarski, T., Zumbo, V., 2012. Application of geophysical measurements for assessing the role of fissures in water infiltration within a clay landslide (Trièves area, French

Bombard, J.-P., 1968. Une approche des problèmes posés par l'étude des mouvements de terrains. Thèse de Géologie, Faculté des Sciences de Grenoble, Grenoble, (in French).

683 Canny, J., 1986. A Computational Approach to Edge Detection. Pattern Analysis and Machine Intelligence, IEEE Transactions on 8, 679-698.

Canty, M.J., Nielsen, A.N., 2008. Automatic radiometric normalization of multitemporal satellite imagery with the iteratively re-weighted MAD transformation. Remote Sensing of Environment 112, 1025-1036. 
Chaudhuri, S., Chatterjee, S., Katz, N., Nelson, M., Goldbaum, M., 1989. Detection of blood vessels in retinal images using two-dimensional matched filters. IEEE Transactions on Medical Imaging 8, 263-269.

Chowdhury, R.N., Zhang, S., 1991. Tension cracks and slope failure. In: R.J. Chandler (Ed.), Proceedings of the International Conference on Slope Stability Engineering: developments and applications. Institution of Civil Engineers, Isle of Wight, pp. 27-32.

Cruden, D.M., Varnes, D.J., 1996. Landslides Types and Processes. In: A.K. Turner, R.L. Schuster (Eds.), Landslides: Investigation and Mitigation. Transportation Research Board, Special Report 247, National Academy of Sciences, Washington D.C, pp. 36-75.

Davis, G.H., Reynolds, S.J., 1996. Structural Geology of Rocks and Regions. Wiley, pp. 776.

Eisenbeiss, H., 2009. UAV Photogrammetry. PhD, ETH Zürich, Zürich.

Espinosa, A., 2009. Analysis and quantification of preferential flow on the Super-Sauze landslide. MSc, Delft University of Technology, Delft, Netherlands, $80 \mathrm{pp}$.

Fleming, R.W., Baum, R.L., Giardino, M., 1999. Map and description of the active part of the slumgullion landslide, Hinsdale County, Colorado, Geologic Invstigations Series Map I-2672. U.S. Geologcial Survey, Denver, Colorado.

Fleming, R.W., Johnson, A.M., 1989. Structures associated with strike-slip faults that bound landslide elements. Engineering Geology 27, 39-114.

Glenn, N.F., Streutker, D.R., Chadwick, D.J., Thackray, G.D., Dorsch, S.J., 2006. Analysis of LiDARderived topographic information for characterizing and differentiating landslide morphology and activity. Geomorphology 73, 131-148.

González, R.C., Woods, R.E., 2008. Digital Image Processing, 3rd Edition. Prentice Hall.

Gotway, C.A., Young, L.J., 2002. Combining incompatible spatial data. Journal of the American Statistical Association 97, 632-648. 
712 Graham, D.J., Rollet, A.-J., Piégay, H., Rice, S.P., 2010. Maximizing the accuracy of image-based surface sediment sampling techniques. Water Resources Research 46, http://dx.doi.org/doi:10.1029/2008WR006940.

715 Grandjean, G., Bitri, A., Krzeminska, D.M., 2011. Characterisation of a landslide fissure pattern by integrating seismic azimuth tomography and geotechnical testing. Hydrological Processes 26,

Günther, A., Carstensen, A., Pohl, W., 2004. Automated sliding susceptibility mapping of rock slopes. Natural Hazards and Earth System Sciences 4, 95-102.

Harper, J.T., Humphrey, N.F., Pfeffer, W.T., 1998. Crevasse patterns and the strain-rate tensor: a highresolution comparison. Journal of Glaciology 44, 68-76.

Hoek, E., Bray, J.W., 1981. Rock Slope Engineering. The Institution of Mining and Metallurgy, London.

Hong, G., Zhang, Y., 2008. A comparative study on radiometric normalization using high resolution satellite images. International Journal of Remote Sensing 29, 425-438.

Hoover, A.D., Kouznetsova, V., Goldbaum, M., 2000. Locating blood vessels in retinal images by piecewise threshold probing of a matched filter response. IEEE Transactions on Medical Imaging $19,203-210$.

Jaboyedoff, M., Baillifard, F., Couture, R., Locat, J., Locat, P., 2004. Toward preliminary hazard assessment using DEM topographic analysis and simple mechanical modeling by means of sloping local base level,. In: W.A. Lacerda, M. Ehrlich, A.B. Fontoura, A. Sayão (Eds.), Landslides: Evaluation and Stabilization. Taylor \& Francis Group, London, pp. 199-205.

Ke, C.C., Chen, C.S., Tu, C.H., 2008. Determination of fracture toughness of anisotropic rocks by boundary element method. Rock Mechanics and Rock Engineering 41, 509-538.

735 Khattak, G.A., Owen, L.A., Kamp, U., Harp, E.L., 2010. Evolution of earthquake-triggered landslides in the Kashmir Himalaya, northern Pakistan. Geomorphology 115, 102-108. 
Krauskopf, K.B., Feitler, S., Griggs, A.B., 1939. Structural features of a landslide near Gilroy, California. The Journal of Geology 47, 630-648.

Krzeminska, D.M., Bogaard, T.A., van Asch, T.W.J., van Beek, L.P.H., 2011. A conceptual model of the hydrological influence of fissures on landslide activity. Hydrology and Earth System Sciences 8,

Lampert, T.A., O’Keefe, S.E.M., 2011. A detailed investigation into low-level feature detection in 11039-11073.

Lampert, T.A., Stumpf, A., Gancarski, P., submitted. An Empirical Study into Expert Agreement and Ground Truth Estimation, IEEE Conference on Computer Vision and Pattern Recognition, Portland, USA.

Malet, J.-P., Auzet, A.-V., Maquaire, O., Ambroise, B., Descroix, L., Esteves, M., Vandervaere, J.-P., Truchet, E., 2003. Soil surface characteristics influence on infiltration in black marls: application

Malet, J.P., 2003. Les 'glissements de type écoulement' dans les marnes noires des Alpes du Sud. to the Super-Sauze earth flow (southern Alps, France). Earth Surface Processes and Landforms Morphologie, fonctionnement et modélisation hydro-mécanique. PhD, Université Louis Pasteur, $28,547-564$. Strasbourg (in French).

Malet, J.P., Laigle, D., Remaître, A., Maquaire, O., 2005a. Triggering conditions and mobility of debris flows associated to complex earthflows. Geomorphology 66, 215-235.

Malet, J.P., van Asch, T.W.J., van Beek, R., Maquaire, O., 2005b. Forecasting the behaviour of complex landslides with a spatially distributed hydrological model. Natural Hazards and Earth System Sciences $5,71-85$.

Mallast, U., Gloaguen, R., Geyer, S., Rödiger, T., Siebert, C., 2011. Semi-automatic extraction of lineaments from remote sensing data and the derivation of groundwater flow-paths. Hydrol. Earth Syst. Sci. Discuss. 8, 1399-1431. 
762 Marr, D., Hildreth, E., 1980. Theory of edge detection. Proceedings of the Royal Society of London Series B, Biological Sciences 207, 187-217.

764 Martha, T., Kerle, N., van Westen, C.J., Kumar, K., 2010. Characterising spectral, spatial and morphometric properties of landslides for semi-automatic detection using object-oriented methods. Geomorphology 116, 24-36

Matheson, G.D., 1983. Rock Stability Assessment in Preliminary Site Investigations - Graphical Methods, Transport and Road Research Laboratory, Crownthorne.

McCalpin, J., 1984. Preliminary age classification of landslides for inventory mapping, 21st Annual Engineering Geology and Soils Engineering Symposium, Moscow, Idaho, pp. 99-111.

Meisina, C., 2006. Characterisation of weathered clayey soils responsible for shallow landslides. Natural Hazards and Earth System Sciences 6, 825-838.

773 Melton, F.A., 1959. Aerial photographs and structural geomorphology. Journal of Geology 67, 351-370.

774 Mendonca, A.M., Campilho, A., 2006. Segmentation of retinal blood vessels by combining the detection of centerlines and morphological reconstruction. IEEE Transactions on Medical Imaging 25, 1200-1213.

Metzger, W., 1975. Gesetze des Sehens, 3. Auflage. Waldemar Kramer, Frankfurt am Main.

Niethammer, U., James, M.R., Rothmund, S., Travelletti, J., Joswig, M., 2011a. UAV-based remote sensing of the Super-Sauze landslide: Evaluation and results. Engineering Geology 128, 2-11.

Niethammer, U., Rothmund, S., James, M.R., Travelletti, J., Joswig, M., 2010. UAV-based remote sensing of landslides. ISPRS Commission V Mid Term Symposium XXXVIII, Part 5, 496-501.

782 Niethammer, U., Rothmund, S., Schwaderer, U., Zeman, J., Joswig, M., 2011b. Open source imageprocessing tools for low cost UAV-based landslide investigations. International archives of the photogrammetry, remote sensing and spatial information sciences Vol XXXVIII-1/C22.

Otsu, N., 1979. A threshold selection method from gray-level histograms. IEEE Transactions on Systems, Man and Cybernetics 9, 62-66 
Papari, G., Petkov, N., 2011. Edge and line oriented contour detection: State of the art. Image and Vision Computing 29, 79-103.

Parise, M., 2003. Observation of surface features on an active landslide, and implications for understanding its history of movement. Natural Hazards and Earth System Sciences 3, 569-580.

Passchier, C.W., Trouw, R.A.J., 2005. Microtectonics. Springer, Berlin Heidelberg.

792 Pollard, D.D., Fletcher, R.C., 2005. Fundamentals of Structural Geology, Third printing with corrections. 793 Cambridge Universoty Press, New York.

794 Prats, X., Ramírez, J., Delgado, L., Royo, P., 2012. Regulations and Requirements. In: P. Angelov (Ed.), 795 In Sense and avoid in UAS: Research and applications. Wiley, West Sussex, UK, pp. 87-117.

796 Priest, S.D., 1993. Discontinuity Analysis for Rock Engineering. Chapman \& Hall, London.

797 Quackenbush, L.J., 2004. A review of techniques for extracting linear features from imagery. Photogrammetric Engineering and Remote Sensing 70, 1383-1392.

799

Riedel, W., 1929. Zur Mechanik geologischer Brucherscheinungen. Zentralblatt für Mineralogie, Geologie und Paläontologie B 354-368.

Sander, P., Minor, T.B., Chesley, M.M., 1997. Ground-water exploration based on lineament analysis and reproducibility tests. Ground Water 35, 888-894.

Schott, J.R., Salvaggio, C., Volchok, W.J., 1988. Radiometric scene normalization using pseudoinvariant features. Remote Sensing of Environment 26, 1-16.

Schulson, E.M., Duval, P., 2009. Creep and Fracture of Ice. Cambridge University Press, New York.

Selby, M.J., 1993. Hillslope Materials and Processes, 2nd Edition. Oxford University Press, Oxford.

Serra, J., 1982. Image Analysis and Mathematical Morpholgy. Academic Press, Orlando, Florida.

Shao, Y., Guo, B., Hu, X., Di, L., 2011. Application of a fast linear feature detector to road extraction from remotely sensed imagery. IEEE Journal of Selected Topics in Applied Earth Observations and Remote Sensing 4, 626-631.

Shreve, R.L., 1966. Sherman landslide, Alaska. Science 154, 1639-1643. 
812 Shruthi, R.B.V., Kerle, N., Jetten, V., 2011. Object-based gully feature extraction using high spatial resolution imagery. Geomorphology 134, 260-268.

814 Soares, J.V.B., Leandro, J.J.G., Cesar, R.M., Jelinek, H.F., Cree, M.J., 2006. Retinal vessel segmentation using the 2-D Gabor wavelet and supervised classification. IEEE Transactions on Medical Imaging 25, 1214-1222.

Sofka, M., Stewart, C.V., 2006. Retinal vessel centerline extraction using multiscale matched filters, confidence and edge measures. IEEE Transactions on Medical Imaging 25, 1531-1546.

820

Sowers, G.F., Royster, D.L., 1978. Field Investigation. In: R.L. Schuster, R.J. Krizek (Eds.), Landslides: Analysis and Control. Transportation Research Board, Special Report 176, National Academy of Science, Washington, D.C., pp. 81-111.

823

Stumpf, A., Kerle, N., 2011. Object-oriented mapping of landslides using Random Forests. Remote Sensing of Environment 115, 2564-2577.

824 Stumpf, A., Lampert, T.A., Malet, J.-P., Kerle, N., 2012. Multi-scale line detection for landslide fissure mapping, International Geoscience and Remote Sensing Symposium, Munich, Germany, pp. 4.

Frost \& Sullivan, 2007. Study Analysing the Current Activities in the Field of UAV, European Comission Enterprise and Industry Directorate-General.

Tarboton, D.G., Bras, R.L., Rodriguez-Iturbe, I., 1991. On the extraction of channel networks from digital elevation data. Hydrological Processes 5, 81-100.

Tchalenko, J.S., 1970. Similarities between Shear Zones of Different Magnitudes. Geological Society of America Bulletin 81, 1625-1640.

Ter-Stephanian, G., 1946. On the landslide cracks classification. Bulletin of the Academy of Sciences of the Armenian SSR 10, 65-80 (in Russian with abstracts in Armenian and English). caractérisation des mécanismes de glissements-coulées. PhD, Université de Caen BasseNormandie, Strasbourg. 
Travelletti, J., Malet, J.P., 2012. Characterization of the 3D geometry of flow-like landslides: A methodology based on the integration of heterogeneous multi-source data. Engineering Geology $128,30-48$.

Trimble, 2011. eCognition Developer 8.64.0 Reference Book. Trimble Documentation, München.

Tveite, H., Langaas, S., 1999. An accuracy assessment method for geographical line data sets based on buffering. International Journal of Geographical Information Science 13, 27-47.

Vallet, J., 2007. GPS/IMU and LiDAR integration to aerial photogrammetry: Development and practical experiences with Helimap System ${ }^{2}$, 27. Wissenschaftlich-Technische Jahrestagung der DGPF, Dreiländertagung, Muttenz.

van Asch, T.W.J., van Beek, L.P.H., Bogaard, T.A., 2009. The diversity in hydrological triggering systems of landslides, The First Italian Workshop on Landslides, Napoli, Italy pp. 151-156.

Vaughan, D.G., 1993. Relating the occurrence of crevasses to surface strain rates. Journal of Glaciology $39,255-266$.

Vicente-Serrano, S.M., Pérez-Cabello, F., Lasanta, T., 2008. Assessment of radiometric correction techniques in analyzing vegetation variability and change using time series of Landsat images. Remote Sensing of Environment 112, 3916-3934.

Walter, M., Arnhardt, C., Joswig, M., 2012. Seismic monitoring of rockfalls, slide quakes, and fissure development at the Super-Sauze mudslide, French Alps. Engineering Geology 128, 12-22.

Walter, M., Niethammer, U., Rothmund, S., Joswig, M., 2009. Joint analysis of the Super-Sauze (French Alps) mudslide by nanoseismic monitoring and UAV-based remote sensing. first break $27,53-$ 60.

Wang, E.Z., Shrive, N.G., 1995. Brittle fracture in compression: Mechanisms, models and criteria. Engineering Fracture Mechanics 52, 1107-1126.

Watts, A.C., Ambrosia, V.G., Hinkley, E.A., 2012. Unmanned Aircraft Systems in Remote Sensing and Scientific Research: Classification and Considerations of Use. Remote Sensing 4, 1671-1692. 
Youssef, A., Maerz, N., Hassan, A., 2009. Remote sensing applications to geological problems in Egypt: case study, slope instability investigation, Sharm El-Sheikh/Ras-Nasrani Area, Southern Sinai. Landslides 6, 353-360.

Zhang, B., Zhang, L., Zhang, L., Karray, F., 2010. Retinal vessel extraction by matched filter with firstorder derivative of Gaussian. Computers in Biology and Medicine 40, 438-445.

869 Fig. 1. Generic types of surface fissures and their typical spatial occurrence within a landslide mass. (a) 870 Modes of fracture propagation: mode I (opening), II (sliding) and III (tearing). (b) Fissures developing 871 predominately in mode I and resulting from tensile stress. (c) Fissures developing predominately in mode 872 I and resulting from shear stress. (d) Fissures developing predominantly in mode I resulting from 873 compressive stress and lateral expansion. The central figure is adapted from (Sowers and Royster, 1978).

875 Fig. 2. Oblique view of the Super-Sauze landslide combining a hillshade image derived from an airborne 876 LiDAR DTM (July 2009) and a UAV image (October 2008). (a) The main scarp (hashed black line), 877 transport and accumulation zone (black outline), and the area of interest for the multi-temporal analysis 878 (white square) are indicated. UAV image subsets show (b) compression ridges, (c) longitudinal fissures, 879 (d) diagonal fissures at the boundary of the active part, and (e) and transversal fissures.

881 Fig. 3. Subsets of orthophotographs (see location in the white bounding box in Fig. 2a) acquired at five 882 different dates with details of the acquisition systems and image ground resolutions. 
884

885

886

887

888

889

890

891

892

893

894

895

896

897

898

899

900

901

902

903

904

905

906

907
Fig. 4. (a) Subset (see extent in Fig. 3) of the UAV image from October 2008 showing typical fissure patterns and (I-IV) grey-value profiles (green channel) approximated with Gaussian curves. (b) Field terrestrial photograph taken in October 2009.

Fig. 5. Illustration of the principles of the Gaussian filtering for (a-c, f-h) a simplified 1-D case, (d, i) a $3 \mathrm{D}$ visualization of $2 \mathrm{D}$ filters and $(e, j)$ the filter responses for the image subset in Fig. 4a. See text for details.

Fig. 6. Strategy used to connect broken line segments. (a) Working principle of the hit- and miss transform, (b) hit structures, (c) miss structures and (d) respective rotations used for the plausible pixel neighbourhoods.

Fig. 7. Illustration of the automatic threshold detection for the intermediate mapping of vegetation. (a) Subset of the October 2008 image at the toe of the landslide. (b) Ratio blue. (c) Initial thresholding at ratio blue $<0.33$ to obtain vegetation candidates (yellow). (d) Histogram of the vegetation candidates with the automatically selected threshold. (e) Final map of the vegetation (green).

Fig. 8. Illustration of the object-oriented post-processing routine. (a) Fissure candidates that overlapped with linear structures. (b) Linear structure detected at a ten times greater filter scale. The fissure candidates aligned with the linear structures at angles below $\pm 13^{\circ}$ were removed.

Fig. 9. Example of comparison of the obtained fissure maps with the expert mapping for October 2010 (fissures in red). (a) Area with relatively high agreement of the mapped fissure patterns. (b) Area with relatively high rate of false negatives and false positives. The scale of the representations corresponds approximately to the scale used for the expert mapping (1:250). 
909 Fig. 10: Receiver operating characteristics (ROC) plots for the fissured area at different map resolutions.

910 The sky conditions for the five different dates are indicated.

912 Fig. 11. Correlation between fissure density estimates at $5 \mathrm{~m}$ raster resolution based on semi-automatic

913 detections and expert mappings from the five images. The bar plots at the bottom display the $\mathrm{R}^{2}$ 914 coefficient at different raster resolutions.

916 Fig. 12. Rose diagram plots with mean orientation (red line) and error statistics for the mean fissure 917 orientation per $10 \mathrm{~m}$ grid cell for the test area at the five different dates. For visualization, the rose 918 diagrams where plotted over a hillshade of the landslide surface and the scatterplot angles were centred at $91990^{\circ}$.

921 Fig. 13. Pseudo 3D view showing the landslide dynamics inferred from the fissure patterns detected in the 922 aerial images of (a) May 2007 and (b) October 2008. (c, d, e) Close up views for October 2008 showing 923 inferred landslide dynamics and stress vectors. The results are overlaid on a hillshade model of the 924 topography of the stable bedrock proposed by (Travelletti and Malet, 2012).

Table 1

927 Parameter set of the Gaussian filters scaled according to the respective image resolution.

929 Table 2

930 Summary of the thresholds adopted in the object-oriented post-processing routine. See text for details. 